\title{
Consciousness and attention: on sufficiency and necessity
}

\author{
Jeroen J. A. van Boxtel ${ }^{1 *+}$, Naotsugu Tsuchiya ${ }^{2,3}{ }^{* t}$ and Christof Koch ${ }^{1,4,5}$ \\ Division of Biology, California Institute of Technology, Pasadena, CA, USA \\ 2 Division of Humanities and Social Sciences, California Institute of Technology, Pasadena, CA, USA \\ ${ }^{3}$ Brain Science Institute, Tamagawa University, Tokyo, Japan \\ ${ }^{4}$ Division of Engineering and Applied Science, California Institute of Technology, Pasadena, CA, USA \\ ${ }^{5}$ Brain and Cognitive Engineering, Korea University, Seoul, Korea
}

\section{Edited by:}

Hakwan Lau, Columbia University, USA

Reviewed by:

Bob Kentridge, Durham University, UK Jerome Sackur, École Normale

Supérieure, France

*Correspondence:

Jeroen J. A. van Boxtel, Division of

Biology, California Institute of

Technology, 216-76, Pasadena, CA

91125, USA

e-mail: jeroen@caltech.edu;

Naotsugu Tsuchiya. Laboratory for

Adaptive Intelligence, Brain Science Institute, RIKEN, 2-1 Hirosawa,

Wako-shi, Saitama 351-0198, Japan.

e-mail:naotsu@gmail.com

${ }^{\dagger}$ Jeroen J. A. van Boxtel and Naotsugu

Tsuchiya have contributed equally to

this work.
Recent research has slowly corroded a belief that selective attention and consciousness are so tightly entangled that they cannot be individually examined. In this review, we summarize psychophysical and neurophysiological evidence for a dissociation between top-down attention and consciousness. The evidence includes recent findings that show subjects can attend to perceptually invisible objects. More contentious is the finding that subjects can become conscious of an isolated object, or the gist of the scene in the near absence of top-down attention; we critically re-examine the possibility of "complete" absence of top-down attention. We also cover the recent flurry of studies that utilized independent manipulation of attention and consciousness. These studies have shown paradoxical effects of attention, including examples where top-down attention and consciousness have opposing effects, leading us to strengthen and revise our previous views. Neuroimaging studies with EEG, MEG, and fMRI are uncovering the distinct neuronal correlates of selective attention and consciousness in dissociative paradigms. These findings point to a functional dissociation: attention as analyzer and consciousness as synthesizer. Separating the effects of selective visual attention from those of visual consciousness is of paramount importance to untangle the neural substrates of consciousness from those for attention.

Keywords: attention, consciousness, psychophysics, neuroimaging

\section{INTRODUCTION}

Although often used in everyday speech and in the scholarly literature, "selective attention" and "consciousness" lack clear definitions. Partly because of this deficit there exists a lively debate on the relationship between the two. For clarity, we start with stating our usage of the terms "attention" and "consciousness". We use the term "attention" to imply selective attention, rather than the processes that control the overall level of arousal and alertness. We focus on topdown, goal-directed endogenous attention and not on bottom-up, saliency-driven exogenous attention (Itti and Koch, 2001). We do so because top-down attention and consciousness can be independently manipulated without changing the visual inputs (e.g., van Boxtel et al., 2010), while bottom-up attention, almost by definition, needs to be manipulated by changing the physical properties of a cueing stimulus, such as its visual features or its spatio-temporal relationship with a target stimulus. Thus, it is difficult to disentangle bottom-up attention from consciousness (but see Chica et al., 2010). By consciousness, we refer to the content of consciousness (sometimes also referred to as awareness), and not to states or levels of consciousness (e.g., wakefulness, dreamless sleep or coma). Furthermore, we restrict this review to visual attention and visual consciousness, as the psychology and the neurophysiology of vision is much better understood than those of other modalities.

It is generally acknowledged that attention and perceptual consciousness share an intimate relationship. When an observer pays attention to an object, he or she becomes conscious of its various attributes; when attention shifts away, the object seems to fade from consciousness. Because of this tight relationship many scholars posit that these two processes are inextricably entangled, if not identical (Posner, 1994; Jackendoff, 1996; Velmans, 1996; Merikle and Joordens, 1997; Mack and Rock, 1998; Chun and Wolfe, 2000; O'Regan and Noe, 2001; Mole, 2008; De Brigard and Prinz, 2010; Prinz, 2010). Others, however, hold the position that attention and consciousness are distinct phenomena, with distinct functions and neuronal mechanisms that can be dissociated through clever experimentation (Wundt, 1874; Iwasaki, 1993; Hardcastle, 1997; Naccache et al., 2002; Lamme, 2003; Woodman and Luck, 2003; Kentridge et al., 2004; Koch, 2004; Baars, 2005; Block, 2005; Bachmann, 2006; Dehaene et al., 2006; Koch and Tsuchiya, 2007; Tsuchiya and Koch, 2008a,b).

Recently, there has been a growing interest in the relationship between attention and consciousness. Many studies have shown a dissociation between attention and consciousness using psychophysics and neurophysiological measurements such as EEG, MEG, and fMRI. This review gives an update of our previous overviews (Koch and Tsuchiya, 2007; Tsuchiya and Koch, 2008a,b). In the first half, we closely examine the question of the necessity and sufficiency of attention for conscious perception. In the second half, we review experiments published after our previous reviews. These studies contrast the effects of attention and consciousness for a given percept by independently manipulating the two. Some studies successfully dissociate attention and consciousness, while some even show opposing effects of attention and consciousness.

As consciousness is notoriously difficult to define, we here use an operational definition. We will equate consciousness for an object or event, say a stationary grating, with stimulus visibility. As long as the 
subject can see the grating, he or she is conscious of the grating or of one or more of its attributes (its location, orientation, contrast). Other operational definitions involve subjective confidence or wagering procedures (e.g., Persaud et al., 2007; Wilimzig et al., 2008).

\section{FUNCTIONAL CONSIDERATIONS IMPLY A DISSOCIATION}

The visual system is constantly bombarded with information, leading to a data deluge that cannot be processed in real time; on the order of one megabyte of raw information exits the retina every second. The prime goal of visual attention therefore is to select information to meet current behavioral goals (James, 1890; Reynolds and Chelazzi, 2004). By definition this implies a relative decrease of processing resources for non-attended locations or features. Such attentional selection can be based on bottom-up, exogenous saliency-based factors or top-down, endogenous, goal-directed factors (James, 1890; Braun and Julesz, 1998; Duncan, 1998; Koch, 2004). Top-down attention, the focus of this review, selects a portion of the input defined by a circumscribed region in space (spatial or focal attention), by a particular feature (feature-based attention), or by an object (object-based attention) for further processing.

Consciousness is surmised to have functions almost diametrically opposite to those of attention. It does not select information. Rather, proposed roles of consciousness include summarizing all relevant information pertaining to the current state of the organism and its environment and making this compact summary accessible to the planning stages of the brain, detecting anomalies and errors, decision making, language, inferring the internal state of other animals, setting long-term goals, making recursive models, and rational thought. This integrative aspect is emphasized by the Integrated Information Theory of consciousness (Tononi, 2004, 2008). These functions also suggest that consciousness may be important at longer timescales than attention is, and may not be operating at the same level in the visual hierarchy.

From this viewpoint, we can regard selective, focal attention as an analyzer and consciousness as a synthesizer. To the extent that one accepts that attention and consciousness have different functions, one has to accept that they cannot be the same process, and anticipate dissociations between the two.

\section{THE FOUR-FOLD WAY OF PROCESSING VISUAL EVENTS AND BEHAVIORS}

Previously, we argued that each behavior or percept can be categorized within a $2 \times 2$ design matrix, defined by whether it gives rise to consciousness and whether it requires top-down attentional amplification (Koch and Tsuchiya, 2007).

The lower right quadrant of our attention $\times$ consciousness design matrix (Table 1) is filled with behaviors or percepts in which attention is necessary for them to give rise to consciousness. For example, an unexpected and unfamiliar stimulus requires topdown attention in order to be consciously perceived. Otherwise, such a stimulus goes unnoticed, a phenomenon called inattentional blindness (Mack and Rock, 1998).

At the top-left of the table are behaviors or percepts that do not require the deployment of top-down attention, and that can occur in the absence of conscious perception. For instance, a perceptually
Table 1 | A four-fold classification of percepts and behaviors depending on whether or not top-down attention is necessary and whether or not these percepts and behaviors give rise to phenomenal consciousness. Different percepts and behaviors are grouped together according to these two, psychophysically defined, criteria.

\begin{tabular}{lll}
\hline & $\begin{array}{l}\text { Can be found without } \\
\text { consciousness }\end{array}$ & $\begin{array}{l}\text { Percepts/behaviors } \\
\text { that give rise to } \\
\text { consciousness }\end{array}$ \\
\hline $\begin{array}{ll}\text { Top-down attention } \\
\text { is not required }\end{array}$ & $\begin{array}{l}\text { Formation of } \\
\text { afterimages } \\
\text { Rapid vision (<120 ms) }\end{array}$ & $\begin{array}{l}\text { Pop-out } \\
\text { Iconic memory }\end{array}$ \\
& $\begin{array}{l}\text { Zombie behaviors } \\
\text { Top-down attention }\end{array}$ & $\begin{array}{l}\text { Animal and gender } \\
\text { detection in dual-tasks }\end{array}$ \\
& $\begin{array}{l}\text { Priming } \\
\text { Adaptation }\end{array}$ & Partial reportability \\
\hline Processing of objects & Working memory \\
Visual search & $\begin{array}{l}\text { Detection and } \\
\text { discrimination of } \\
\text { Thoughts }\end{array}$ & unexpected and \\
& unfamiliar stimuli \\
& Full reportability \\
\hline
\end{tabular}

invisible grating that is not attended will still lead to a visible afterimage (e.g., van Boxtel et al., 2010). That is, the formation of afterimages can be independent of paying attention to the inducer nor of consciously perceiving it.

In the first half of the review, we focus on the rest of the matrix: attention without consciousness (bottom-left) and consciousness without attention (top-right). We examine whether attention is necessary and/or sufficient for consciousness.

While many scholars agree that attention and consciousness are distinct, it is popular to assume that attention is necessary for consciousness. For example, Dehaene et al. (2006) argue that without top-down attention, an event cannot be consciously perceived and remains in a preconscious state. Another view is that attention and consciousness are so intertwined that they cannot be operationally separated (O'Regan and Noe, 2001; De Brigard and Prinz, 2010; Prinz, 2010). Below we will briefly review lines of research that have shaped this debate.

\section{EVIDENCE FOR A TIGHT LINK BETWEEN ATTENTION AND CONSCIOUSNESS}

Evidence for a tight link between attention and consciousness comes from research showing that without attention consciousness (or performance) fails. For example, even a very salient object, presented for a few seconds, sometimes goes unnoticed if it is not properly attended: inattentional blindness (Mack and Rock, 1998; Wolfe et al., 2005). Similarly, when a target stimulus draws attention, another target that rapidly follows it in temporal succession is unlikely to be seen: attentional blink (Raymond et al., 1992; Chun and Potter, 1995). Also, a major change between two subsequent images may go unnoticed if attention is not focused on the change: change blindness (Rensink et al., 1997; Tse, 2004; Wolfe et al., 2006). Visual sensitivity decreases when attention is 
distracted: load-induced blindness (Macdonald and Lavie, 2008). Furthermore, damages to various parts of the cortex, including frontal and parietal regions and the temporo-parietal junction (Swan, 2001; Vallar, 2001, 2007), and subcortical areas such as the pulvinar (Werth et al., 1986; Swan, 2001), result in invisibility of stimuli in one hemifield, in particular when there is an competing object in the other hemifield: visual neglect (Driver, 1998). These studies show that when attention is not appropriately directed to an object, its conscious report can fail, supporting the view that attention and awareness are tightly linked.

However, in most of these studies the stimuli are actually perceived, only not in fine detail. When sensitivity is empirically measured under attended and unattended conditions for identical visual inputs, several studies showed nearly no change in detection thresholds (Lee et al., 1999a; Morrone et al., 2002; Tsuchiya and Braun, 2007). In particular, detection of an isolated object is rarely affected by attention (Braun and Julesz, 1998). In fact, in loadinduced blindness (Macdonald and Lavie, 2008), the $d$ ' values are far greater than 0 (i.e., $>1$ ). That is, the stimuli are often perceived, a condition far from true "blindness".

Sometimes, however, a relatively large stimulus or change can go unnoticed when attention is not properly directed, as mentioned above. We believe this is because subjects do perceive the gist of the image correctly, interfering detection of a less meaningful change in the scene as if it was filled in by the gist. In fact, when a stimulus or image change is related to the gist of the scene, attention-related blindness rarely occurs. For example, when natural images are abruptly and totally unexpectedly flashed, inattentional blindness was not observed. That is, subjects can describe the gist of these photos (Mack and Rock, 1998). Similarly, the attentional blink decreases when two subsequent target stimuli differ in their gist compared to when they contain the same gist (Evans and Treisman, 2005; Einhäuser et al., 2007). The case of change blindness is perhaps most telling. A most effective demonstration of change blindness utilizes two photographs with an identical gist (e.g., soldiers near an airplane) with a change that does not modify the gist (e.g., airplane with or without an engine). However, if one uses a minor change that alters the gist between two images (for example, "a $\log$ immediately in the path of a man kayaking down a river was changed into another kayak," Sampanes et al., 2008), observers notice the change much faster than when the gist did not change (e.g., the log was replaced by a rock) (Sampanes et al., 2008).

We conclude that attentional reduction does not usually result in invisibility of an isolated object and that a large change can be missed as long as it does not alter the gist of the scene. Attention and consciousness may not be coupled as tightly as has been thought even in the above cases.

\section{EVIDENCE FOR A DISSOCIATION BETWEEN ATTENTION AND CONSCIOUSNESS}

Due to the recent surge in research on attention and consciousness, there is now ample evidence for a dissociation between the two processes. There are two sides to this story that are of particular interest: Can attention be deployed to a stimulus attribute, object or event without giving rise to consciousness of that attribute, object or event? (bottom-left quadrant in Table 1); and, can one be conscious of something without paying attention to it? (top-right quadrant in Table 1). From the point of view of consciousness, the first question asks whether attention is sufficient to cause consciousness, while the second one asks whether attention is necessary to cause consciousness (or whether only attentionally selected items can enter into consciousness). We will review these questions below.

\section{ATTENTION WITHOUT CONSCIOUSNESS}

Can observers deploy attention to a stimulus that is not accessible to consciousness? The answer now seems quite definitely: yes, they can. The evidence comes from (1) the attentional manipulation of non-conscious priming and adaptation and (2) the effects of invisible stimuli on attentional cueing.

Behavioral (Naccache et al., 2002; Ansorge and Neumann, 2005; Melcher et al., 2005; Sumner et al., 2006; Kentridge et al., 2008; Finkbeiner and Palermo, 2009; Tapia et al., 2010; Van den Bussche et al., 2010) and neuronal (Kiefer and Brendel, 2006) non-conscious priming is enhanced by spatial (Kentridge et al., 2008; Finkbeiner and Palermo, 2009; Van den Bussche et al., 2010), feature-based (Melcher et al., 2005; Tapia et al., 2010), or temporal (i.e., cueing when the prime or targets appear) (Naccache et al., 2002) attention. So far, there is no evidence that object-based attention can give rise to non-conscious priming (Tapia et al., 2010).

Likewise, the strength of adaptation to perceptually invisible (attributes of) stimuli such as orientation (He et al., 1996; Montaser-Kouhsari and Rajimehr, 2004; Kanai et al., 2006; Bahrami et al., 2008a,b; Shin et al., 2009) or the gender of faces (Shin et al., 2009) is increased by enhancing spatial and feature-based attention to these features. When the invisible orientation is defined by illusory contours, spatial attention is even necessary for adaptation (Montaser-Kouhsari and Rajimehr, 2004).

A further piece of evidence comes from a blindsight patient GY. Though GY cannot consciously perceive visual stimuli in his contralesional (blind) visual field, he can be primed by a cue that attracts attention to his blind visual field. This is true even though the cue itself and the target are both invisible (Kentridge et al., 1999a,b, 2004).

The existence of attentional deployment without conscious registration of a stimulus is also supported by studies that showed attentional cueing effects on sub-threshold or invisible stimuli (Rajimehr, 2004; Jiang et al., 2006; Tsushima et al., 2006, 2008; Sato et al., 2007; Lin et al., 2008, 2009; Meteyard et al., 2008; Bauer et al., 2009). Tsushima et al. (2006) (see also Meteyard et al., 2008; Tsushima et al., 2008) even showed that random dot motion stimuli, whose coherency is so low that subjects cannot discriminate their motion direction above chance, are more distracting and detrimental for a concurrently performed central task than motion stimuli with high coherency. Using fMRI, it was shown that compared to supra-threshold motion, sub-threshold motion evokes stronger hemodynamic activation in the motion sensitive cortical area, MT, because the weak sensory stimulus does not activate an area in lateral prefrontal cortex (LPFC) that is presumed to be responsible for inhibiting distracting motion-related activity in MT. Taken together, these studies demonstrate attention can be directed toward and away from a stimulus or one of its attributes without that stimulus or attribute ever being visible. 


\section{OPEN QUESTIONS AND THE NEURONAL BASIS OF ATTENTION WITHOUT CONSCIOUSNESS}

While top-down attention can operate without giving rise to consciousness, many open questions remain. For example, what is the nature of attentional selection of invisible stimuli? Can the representation of an invisible "object" be modulated by any type of attention or only indirectly via temporal, spatial or feature-based attention, yet not object-based attention (De Brigard and Prinz, 2010; Prinz, 2010; Tapia et al., 2010)? Can attention bind features of an invisible object (Lin and $\mathrm{He}, 2009)$ ? As to this last question, some evidence from a Balint's patient (Wojciulik and Kanwisher, 1998) suggest that consciousness is not required for binding (but see Tapia et al., 2010). Attention is not a unitary concept and it is quite plausible that some components of attention, such as object-based attention, may be very difficult to separate empirically from consciousness. These are unresolved issues.

Another question is whether the modulation of invisible stimuli by spatial- or feature-based attention is the rule rather than the exception (Finkbeiner and Palermo, 2009; Shin et al., 2009)? Conventional psychophysical methods, such as binocular rivalry (Chong et al., 2005), have failed to find any attentional modulation of invisible stimuli. However, an fMRI study by Bahrami et al. (2007) showed enhanced BOLD activity at the location of invisible images of tools during a low-load attentional condition at fixation. The authors interpret this as hemodynamic evidence for increased attentional processing of the invisible stimuli in V1 (with a similar trend in V2 and V3). It would be important to understand what kind of stimuli, tasks, and techniques result in strong attentional effects on perceptually invisible stimuli and what these effects entail. For example, synchrony or coherence in a population of spiking neurons (Womelsdorf and Fries, 2007) may be responsible for the attentional selection of invisible stimuli but not for consciousness. Another critical question is why the attentional enhancement of neuronal activity is not sufficient for conscious perception (Braun, 2007). Insufficient stimulus strength is probably an important factor (Dehaene et al., 2006).

\section{CONSCIOUSNESS WITHOUT ATTENTION}

If there is attention without consciousness, one can ask whether or not there exists consciousness without attention. Can a subject be conscious of an object or of an attribute of an object without attending to the object or its attribute? We focus on evidence in favor of that view obtained with the dual-task paradigm. Other lines of evidence, including pop-out, iconic memory, and partial reportability, have been reviewed extensively elsewhere (Block, 2007; Koch and Tsuchiya, 2007; Tsuchiya and Koch, 2008a,b; Lamme, 2010).

Top-down attention is employed when there is competition among two or more nearby objects (Desimone and Duncan, 1995). In fact, almost all the neurophysiological studies of visual attention employ stimulus configurations that engender competition of resources, for example, by placing two objects within a receptive field of a recorded neuron. Without competition, that is when a single stimulus is presented in an otherwise empty field, it is very difficult to observe any top-down attentional modulation (Reynolds and Chelazzi, 2004). At the perceptual level, if a display contains only a single object in isolation, subjects become aware of it in any attentional state. This simple fact seems to undermine the argument that top-down attentional amplification from the frontal area is always necessary for consciousness (Dehaene et al., 2006).
When there is competition among objects, top-down attention exerts a major gating role for consciousness, yet not all the aspects of vision are affected equally. In the dual-task paradigm, spatial attention is focused at fixation by a demanding task, while performance is measured on a simultaneously presented peripheral stimulus. Dualtask studies have shown that simple detection and discrimination of a stimulus in a pop-out array is not compromised when attention is drawn away (Braun and Sagi, 1990; Braun and Julesz, 1998). Furthermore, the gist of a natural scene picture as well as gender and identity of a face can be perceived under dual-task conditions (Figure 1A; Mack and Rock, 1998; Fei-Fei et al., 2002; Reddy et al., 2004, 2006, see also Torralba et al., 2006; Alvarez and Oliva, 2008, 2009). Interestingly, what is considered a change in gist and what not, seems to be affected by expertise (Werner and Thies, 2000). This suggests that consciousness without attention develops in response to extensive experience with a particular class of images. (It is currently unknown why some classes of extensive training result in reduction of consciousness (action without perception, Milner and Goodale, 2008) while others result in enhancement of consciousness (faces and gist). We believe tackling this problem with neuroscientific tools can be a fruitful research project in the future.)

Discrimination of other stimuli - for example, discriminating an arbitrarily rotated letter "L" from an arbitrarily rotated letter " $T$ " - is severely affected when spatial attention is soaked up by the central task (Figure 1A, right panel). While it cannot be guaranteed that observers deploy no top-down attention what-so-ever to the peripheral stimulus in these dual-tasks experiments, these experiments do show that subjects can perform certain discriminations but not others in the near absence of top-down attention.

Note that these findings are grosso modo in accordance with the data that is argued to provide evidence for a tight link between attention and awareness. Without top-down attention, observers cannot report the details of a scene even though they may erroneously claim to have seen a certain stimulus with high confidence (de Gardelle et al., 2009). Yet, observers often do perceive the gist of the scene and can accurately perceive the category of the object (whether it is a face, a natural scene, a letter, etc.). Even with a mere $30 \mathrm{~ms}$ exposure to natural scenes, followed by a mask, observers can clearly perceive their gist (Biederman, 1972; Fei-Fei et al., 2002) even in the absence of any expectation about what type of scene will be flashed. Within these $30 \mathrm{~ms}$, top-down attentional bias could not have taken effect.

\section{IMAGING STUDIES OF THE DUAL-TASK PARADIGM}

Faces and natural scenes are also extensively studied with fMRI under the divided attention condition (for example, Wojciulik et al., 1998; Vuilleumier et al., 2001; Peelen et al., 2009). Among them, two recent studies employed the dual-task paradigm (Reddy et al., 2007; Houtkamp and Braun, 2010) with a tight control on attentional allocation.

The first study (Reddy et al., 2007) looked at the BOLD response in the fusiform face area (FFA) to faces presented in the periphery under a dual-task condition (a central letter task and a peripheral gender discrimination task). The BOLD response in FFA increased when a face was presented compared to when it was absent, regardless of the attentional state. This activation was equally strong when subjects performed only the gender task and when they carried out 
A
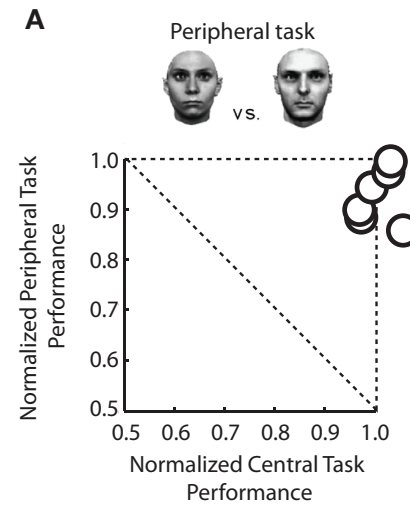

Peripheral task
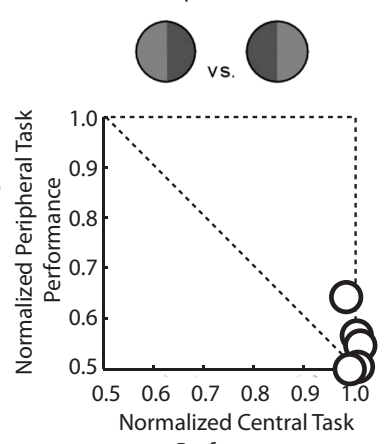

Performance
B

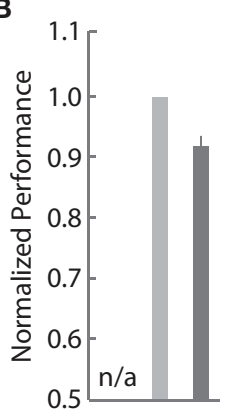

Central task
fMRI

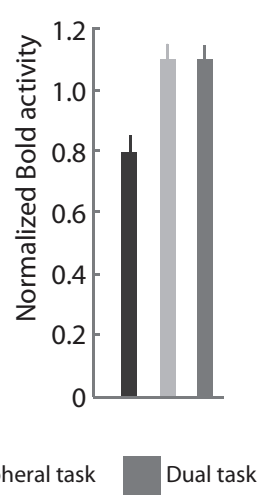

FIGURE 1 | Consciousness without attention: Behavioral performance and fMRI measures in the dual-task paradigm. (A) Typical results in an experiment comparing single task performance (normalized and plotted along the $x$ and $y$ axes, such that they function as a reference for dual-task performance), and dual-task performance. The left panel shows the performance for gender discrimination and the central attention-demanding task when performed simultaneously. Each circle corresponds to the dual-task performance of one subject. Performance is near optimal for both tasks, even though the central letter task is highly demanding. The right panel shows data for a peripheral task involving discriminating a green-red from a red-green bisected disk in combination with the same central task as in the left panel. Although this task seems much simpler from a computational point of view than the one in the left panel, it cannot be performed simultaneously with the central letter task. (B) Left panel: averaged performance in the face gender task with or without the central task, replotted from (A). Right panel: fMRI measures at the location in FFA corresponding to the faces show a pattern very similar to the behavioral data, namely high BOLD activity (and performance) for both peripheral and dual tasks, and reduced activity when the faces are presented but are of no behavioral relevance (Adapted from Reddy et al., 2007). both the gender and the central tasks (Figure 1B, right panel). When only the central task was performed, ignoring the peripheral faces, the FFA activity decreased (but was still above baseline; Figure 1B, right panel). The equal activation in the peripheral-task-only and dual-task conditions is consistent with the psychophysical results (Figure 1B, consciousness without attention) and suggests that there exists a non-spatial "top-down task-based attention" that was present when the peripheral stimulus was task-relevant but did not receive focused attention. This activity may or may not be related to feature-based attention. A similar pattern of results (i.e., sensitivity to unattended stimuli and a task-related activation) has been reported by Peelen et al. (2009) using natural scene stimuli.

A more recent experiment (Houtkamp and Braun, 2010) replicated and expanded the above study, using fractal images, whose angle of rotation or color had to be discriminated. Discrimination of rotation required attention while that of color did not. This study, unlike Reddy et al. (2007), did not mask the peripheral stimulus after the $25 \mathrm{~ms}$ presentation window. Performance for the rotation discrimination in the unmasked condition was much better than in the masked condition. The increased performance in the unmasked situations was assumed to result from a delayed attentional shift to the peripheral stimulus, and a read-out of the iconic memory (i.e., a brief, $\sim 500 \mathrm{~ms}$ visual memory of recent visual events; Sperling, $1960)$ at the peripheral location. For the masked stimuli, this attentional shift is also assumed to take place, but because the stimulus is masked, the attentional shift does not improve the behavioral performance. However, because in both cases the attentional shift is presumed to take place, the fMRI signal in both cases should increase at the peripheral location, which was indeed the case in early visual cortex (Houtkamp and Braun, 2010).

These studies show that behaviorally relevant peripheral stimuli activate visual cortex in situations that indicate consciousness in the absence of focused attention. This activity - which is correlated with a near-perfect performance on the masked peripheral task in the (near) absence of attention - could be explained by the potential presence of other forms of attention (Reddy et al., 2007), or by a delayed attentional shift (Houtkamp and Braun, 2010) that is behaviorally non-relevant (because the iconic memory is overloaded with the mask).

These studies have not looked at differences between consciously perceived and non-perceived peripheral stimuli. Future studies are required to find more direct evidence of the neural correlates of consciousness (NCC) without attention.

\section{CRITICISMS OF THE POSITION THAT STIMULUS CONSCIOUSNESS CAN OCCUR WITHOUT ATTENTION}

Some scholars (Prinz, 2010) criticize the dual-task paradigm because the results of these experiments can be explained by factors other than consciousness without top-down attention. They claim that natural stimuli such as faces and scenes draw more attention than a red-green disc, which enables their superior performance under the dual-task condition. However, the paired central task (typically, discriminating a rotated $\mathrm{L}$ among four rotated $\mathrm{Ts}$ or the opposite from five rotated Ls or Ts) has a very tight linear performanceresource function as in Figure 2 (Pastukhov et al., 2009). Thus, any withdrawal of attention toward faces or scenes would result in a drop of performance for the central task. Such a drop has not been observed (Fei-Fei et al., 2002; Reddy et al., 2004, 2006).

Another criticism is that superior performance does not guarantee the presence of consciousness, as is evidenced in non-conscious behaviors in blindsight patients. That is, even though subjects could perform the task very well, they may not have consciously seen the peripheral stimuli. While this is contradicted by the first person experience when performing the task, it may be possible that the link between performance and consciousness is not as strong as intuitively felt. This is an empirical issue that needs to be further 


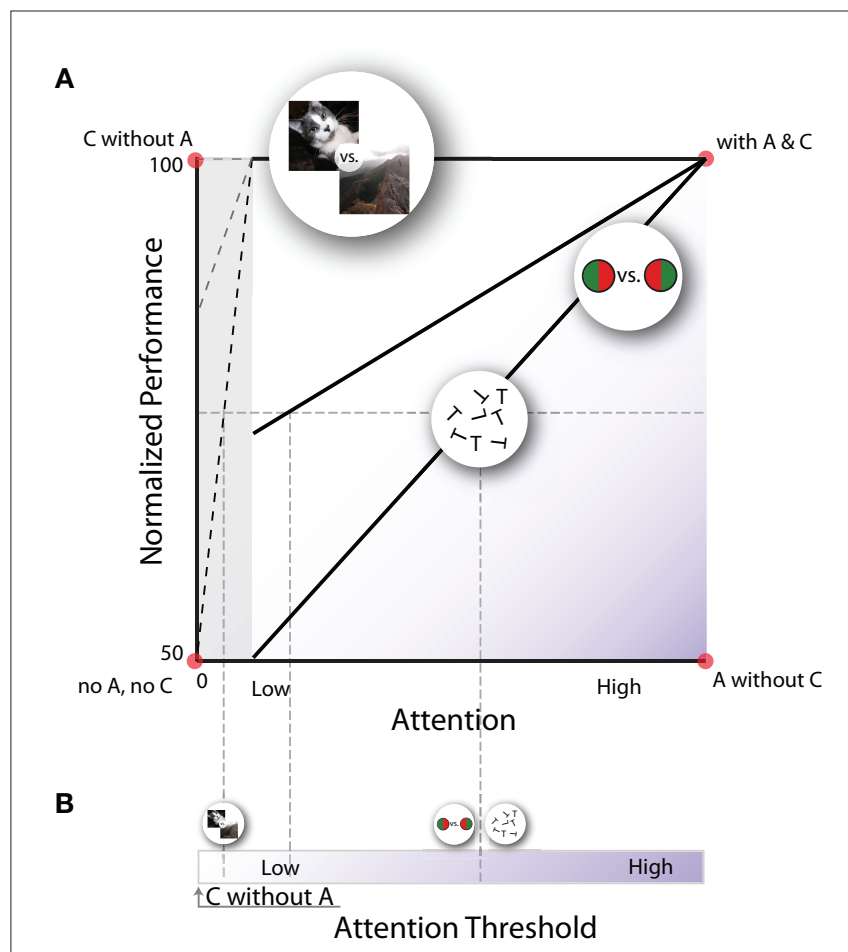

FIGURE 2 | Schematic framework for the relationship between attention and task performance. (A) Performance-resource functions, which show psychophysical performance for a given amount of allocated attention. Each curve describes this relationship for different types of discrimination tasks; some discrimination tasks require a lot of attentional resources (lower diagonal line), others require little (middle diagonal line) or no (top line) attentional resources. Note that each of the four corners in this plot depicts one of the quadrants in Table $\mathbf{1}$ (here $\mathrm{A}=$ attention, and $\mathrm{C}=$ consciousness). (B) Let us assume that when observers can consciously discriminate two stimuli at $75 \%$ correct, they are conscious of the difference to a certain degree. If we accept this, we can measure an attention threshold for a given aspect of visual attribute: how much attention is required to achieve a certain level of conscious discrimination. For example, the attentional threshold for natural scene discrimination (top line) is much lower than those for discriminating red/green bisected discs or rotated letters (bottom line).

studied in the future. For example, one could compare the contents of our perception between conditions of full and divided attention. Under a single task condition (i.e., "full" attention), verbal reports of the gist have been analyzed for a briefly presented and masked natural scene stimulus (Fei-Fei et al., 2007), and it was concluded that, indeed, the gist of a scene could be verbalized in a relatively detailed manner. A similar approach could be taken under dual-task conditions, to analyze the contents of our perception in these situations.

Conclusions from the dual-task experiments rest on one strong assumption about the nature of top-down attention: that attention is a unified and limited resource and all the tasks compete for it, to different degrees. Although most empirical evidence supports such a view (Duncan et al., 1997; Lee et al., 1999b; Pastukhov et al., 2009), multiple-object tracking casts some doubt on this assumption (Alvarez and Cavanagh, 2005). In multiple-object tracking, full attentional resources seem to be independently available for each hemifield to track at least four independently moving items. It is an open question if such a separate and independent resource also exists for tasks that involve faces and natural scenes.

\section{DIFFERENT KINDS OF RELATIONSHIP BETWEEN TASK PERFORMANCE AND ATTENTIONAL RESOURCE}

Figure 2 provides a schematized overview of the previously discussed dual-task experiments. The $y$-axis shows normalized task performance, where $50 \%$ corresponds to chance and $100 \%$ corresponds to maximal performance when the task is performed on its own (i.e., single task performance). The $x$-axis plots the amount of attention needed for the peripheral task (Lee et al., 1999b; Pastukhov et al., 2009). For some tasks, such as discrimination of rotated letters and red-green bisected disc, the task performance and the amount of attention is almost linearly related. When these tasks are used as the central task, they serve as a very sensitive attentional assay, as a canary in a coal mine, because even a minimal shift of attention to the periphery would decrease the central performance. Other tasks show a near complete resistance to attention-deprivation. Such tasks include pop-out (Braun and Sagi, 1990; Braun and Julesz, 1998), scene categorization (Fei-Fei et al., 2002), gender discrimination (Reddy et al., 2004), and face identification (Reddy et al., 2006). In these tasks, performance does not drop when they are performed simultaneously with the highly demanding central task: these tasks do not compete for attention or require only limited attentional resources. Still other tasks need an intermediate amount of attention (e.g., gender discrimination in inverted faces; Reddy et al., 2004).

Consciousness for any one stimulus attribute seems to be an all-or-none process (Koch, 2004; Sergent and Dehaene, 2004), influenced by various factors, including neural variability (Hesselmann et al., 2008). If we crudely assume that, on average, consciousness is reached when performance reaches $75 \%$ in Figure 2A, we can transform panel A into a plot showing the attention threshold at which an observer becomes conscious of different stimuli (Figure 2B).

This way of representing the relationship between attention and consciousness captures the known properties of the psychophysical data. The presentation chosen in Figure 2A also allows for conditions of "attention without consciousness" and "consciousness without attention", while still preserving a positive relationship between attention and consciousness, which researchers intuitively assume to exist. Still, we acknowledge that this depiction is also vulnerable to the criticisms mentioned above (see "Criticisms on consciousness without attention"). Currently, the major obstacle for solving the question of whether there is consciousness without attention is that there is no objective psychophysical way to unambiguously determine a state of "complete absence of attention". It is not known whether the conditions measured in the dual-task paradigms are cases of "very low attention" or "no attention" (gray area on the left in Figure 2A). Nevertheless, different attributes clearly require different amounts of attention to become visible.

\section{ON THE EFFECTS OF ATTENTION AND CONSCIOUSNESS}

So far, we have reviewed studies that directly asked whether attention is necessary and/or sufficient for consciousness. We concluded that attention to a stimulus or an attribute of this stimulus is neither strictly necessary nor sufficient for the stimulus 
or its attribute to be consciously perceived. In the second half of this review, which revolves around many studies that have appeared after our previous reviews, we review a complementary approach to the same question by asking whether the behavioral and neuronal "effects" of attention and consciousness on performance or on other measures are qualitatively similar or not. If the neuronal processes underlying attention and consciousness are largely independent (Dehaene et al., 2006; Koch and Tsuchiya, 2007; Tsuchiya and Koch, 2008a,b), independent manipulation of attention and consciousness might result in different, possibly even opposite, effects at the perceptual, behavioral or neuronal levels.

\section{INDEPENDENT MANIPULATION OF ATTENTION AND CONSCIOUSNESS}

The recent upsurge in studying the relationship between attention and consciousness encouraged experiments employing a full factorial, independent manipulation of attention and consciousness.

Van den Bussche et al. (2010) examined the magnitude of priming effects by independently manipulating prime visibility and spatial attention, leading to a full factorial $2 \times 2$ design. The prime could signal the same behavioral response as the subsequent stimulus (a congruent trial) or an opposite behavioral response (an incongruent trial). When the prime was invisible and unattended, no priming effects were found. Compared to this baseline condition, both attention and awareness increased the priming effects. However, each manipulation contributed to the priming effects in distinct ways: when attention was directed to the invisible prime, the reaction times for the congruent trials were speeded compared to neutral trials, while when visibility was increased for the unattended prime, the reaction times for the incongruent trials were slowed down compared to the neutral condition. In other words, attention to invisible stimuli and visibility of unattended stimuli both enhanced the priming effects, but via distinctive neuronal mechanisms. In visible and attended conditions, both the speeding up of congruent trials and the slowing down of incongruent trials occurred.

Kanai et al. (2006) investigated the magnitude of the tilt aftereffect by independently manipulating attention and consciousness. Attention showed an interesting effect. While feature-based attention increased the size of the aftereffect regardless of the visibility of the adaptor, spatial attention did so only when the adapting stimulus was visible. While later studies showed that spatial attention could modulate the tilt aftereffect (Bahrami et al., 2008a,b) it is still important to know whether different kinds of attention (spatial, feature-based, and object-based) act on visible and invisible stimuli with different sensitivity. As to conscious perception, it had a similar influence as attention, increasing the strength of the aftereffect.

Wyart and Tallon-Baudry (2008) utilized MEG to dissociate neuronal correlates of attention and consciousness. They showed subjects a faint stimulus, which was visible in roughly half of the trials. They manipulated spatial attention by an endogenous cue. In a time-frequency analyses of MEG power, mid-frequency (54-64 Hz) gamma activity was correlated with stimulus visibility for a sustained period, from 250 to $500 \mathrm{~ms}$, in occipital sensors, contralateral to the stimulus. Independent of this awarenessrelated activity, high-frequency $(76-90 \mathrm{~Hz})$ gamma activity was correlated with attention slightly later, for 350-500 ms in parietal sensors. These effects did not interact with each other and suggest that attention and consciousness may have dissociable neuronal correlates.

\section{STUDIES THAT HAVE SHOWN DETRIMENTAL EFFECTS OF ATTENTION}

Under most circumstances in everyday life and most laboratory tasks, attention, and consciousness both improve task performance and/or enhance perceptual experience (Posner, 1994; Jackendoff, 1996; Velmans, 1996; Merikle and Joordens, 1997; Mack and Rock, 1998; Chun and Wolfe, 2000; O'Regan and Noe, 2001; Mole, 2008; De Brigard and Prinz, 2010; Prinz, 2010). Yet if attention and consciousness are supported by different neuronal mechanisms, there might be cases where attention paradoxically impairs performance or reduces the intensity of perceptual experiences. Indeed, such results have been reported in various sensory, cognitive and motor studies, indicating that the effects of attention and consciousness are not monolithic, and can potentially even be opposed to each other.

Top-down attention and learning are generally tightly positively correlated (e.g., Kruschke, 2001). However, in implicit learning, attentively trying to discover an underlying complex rule in an artificial grammar task delays implicit learning and impairs subsequent recognition (Reber, 1976). Similarly, attention to a location impedes task-irrelevant perceptual learning at that location (Choi et al., 2009). During the execution of overlearnt sensory-motor skills, such as dribbling a soccer ball or keyboard typing, attending to the specific skill impairs performance (Beilock et al., 2002; Logan and Crump, 2009). Recognition memory can decrease when the subject's attention is directed to the task-relevant complex kaleidoscopic visual stimulus under certain circumstances (Voss et al., 2008; Voss and Paller, 2009) (Figure 3A). This is quite surprising as recognition memory generally improves the longer the stimulus is visible (e.g., Martini and Maljkovic, 2009; Figure 3B). Although this paradoxical effect seems to occur in a limited situation (i.e., when the to-be-remembered item is difficult to verbalize, when distracters are highly similar to remembered items, etc.), it is worth following up these results in a full-factorial design.

Top-down attention is thought to play a critical role in bringing stimuli into consciousness. However, some visual illusions demonstrate a counterintuitive aspect of attention on the visibility of an object. In motion-induced blindness (MIB), a salient stimulus can be rendered invisible when it is surrounded by moving dots (Bonneh et al., 2001). Yet, paradoxically, when more attention is paid to the salient stimulus the stimulus disappears faster (Figure 3C; Geng et al., 2007; Scholvinck and Rees, 2009). Surprisingly, the more salient the stationary yellow squares, the stronger the suppression (Bonneh et al., 2001). In Troxler fading (Troxler, 1804), a stimulus placed in the visual periphery fades from awareness when fixation is held correctly. This fading happens faster when attention is directed to the peripheral stimulus (Babington Smith, 1961; Lou, 1999). In the attentional blink, observers can see both the first and the second targets better when they are distracted by a simultaneous auditory dual task or encouraged to think about task-irrelevant events (Olivers and Nieuwenhuis, 2005). In all of the above cases, the more subjects try to see some stimulus by paying attention to, the less visible it becomes! 
A

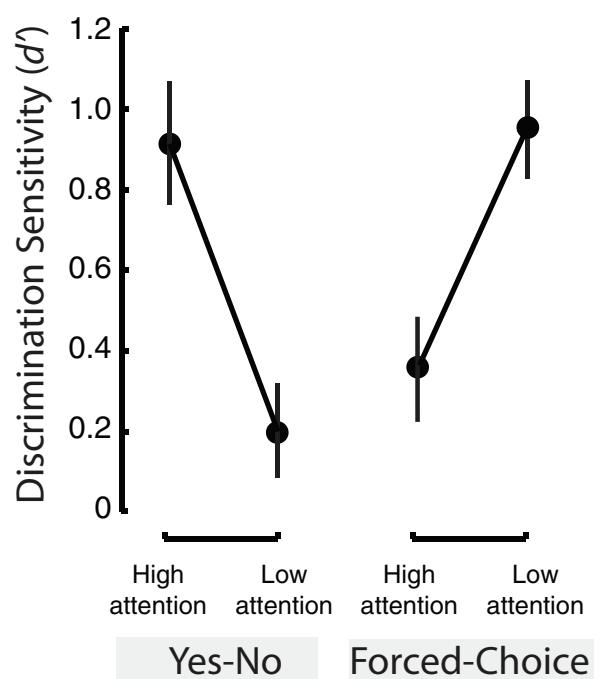

Task type

C

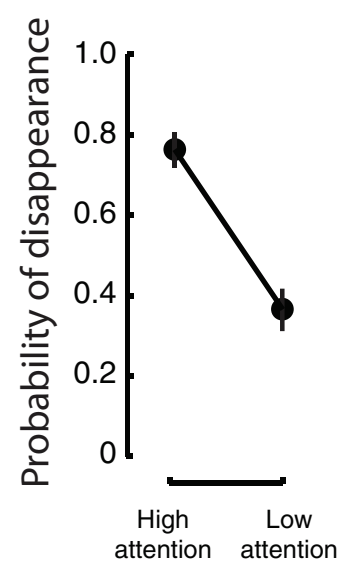

Left target
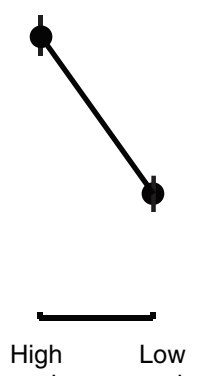

attention attention

Right target

\section{Attended location}

FIGURE 3 | Some detrimental influences of attention, and effects of attention opposite to those of consciousness. (A) When attention is paid to a stimulus it is generally assumed that recognition memory increases. This is true for an explicit memory task (left panel; here, subjects had to report whether or not they had seen a test stimulus), but not for a task tapping more into implicit memory (right panel: subjects were forced to choose which one of two similar fractal stimuli were presented previously). In the latter task, recognition memory decreased when attention was directed toward the to-be-remembered object. This study also shows that the type of report asked from the subject can greatly influence the results (Adapted from Voss et al., 2008) (B) In a task where people had to indicate whether or not a natural image was previously seen,

consciousness, or visibility as expressed in presentation duration, of a

The above-mentioned studies show some paradoxical effects of attention. Note, however, that a complete orthogonal manipulation of attention and consciousness has not been performed in any of these examples. Some more examples of the counterintuitive nature of attention are reviewed elsewhere (Tsuchiya and Koch, 2008b).

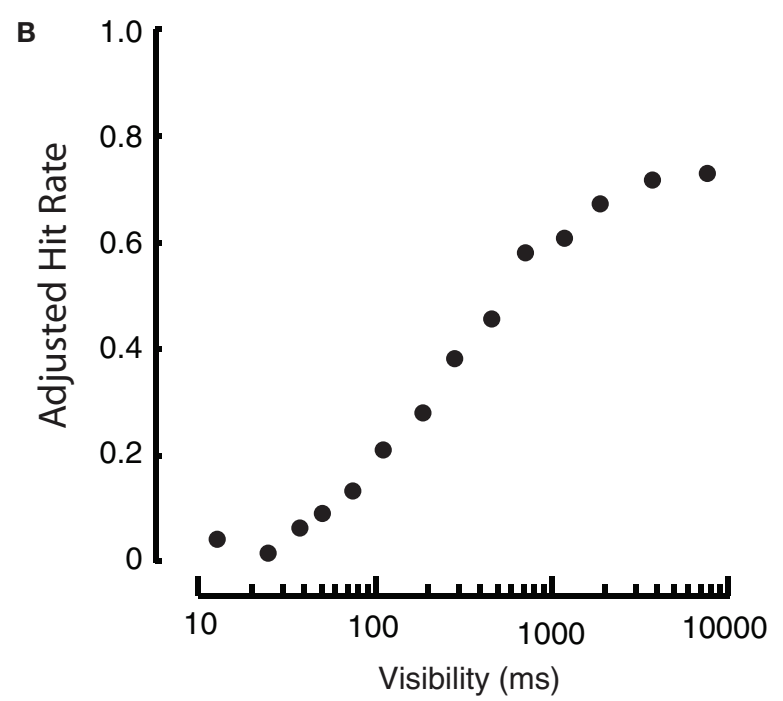

D

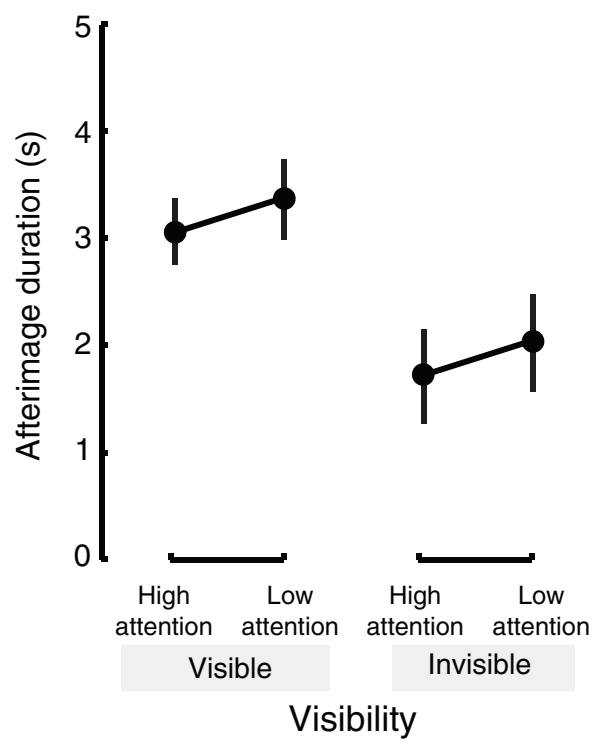

to-be-remembered item causes an increase in performance for recognition memory (as expressed in the adjusted hit-rate for remembered items, corrected for guesses). (Adapted from Martini and Maljkovic, 2009). (C) In motion-induced blindness, paying attention to a stimulus causes that stimulus to disappear with a greater probability (left and right panels: attention is directed to different locations) (Adapted from Scholvinck and Rees, 2009) (D). Attention and consciousness (i.e., visibility) have opposing effects on afterimage duration. When a stimulus is visible (left panel) it will leave a longer afterimage than when it is invisible (right panel). At the same time, paying attention to a stimulus decreases the duration of the afterimage (Adapted from van Boxtel et al., 2010). Note that $(\mathbf{A}, \mathbf{C}, \mathbf{D})$ have a similar layout but that different measures are reported on the $y$-axis, and in the comparisons between the left and right panels.

\section{OPPOSITE EFFECTS OF ATTENTION AND CONSCIOUSNESS ON PERCEPTION BUT NOT ON ADAPTATION}

One of the most striking pieces of evidence for distinctive neuronal processes for attention and consciousness comes from the studies of afterimages. Afterimages were long thought to have their sole 
origin in the retina (Alpern and Barr, 1962; Brindley, 1962; Loomis, 1972, 1978; Sakitt, 1976; Virsu and Laurinen, 1977; Wilson, 1997), which is impervious to attention and awareness-related signals (in mammals, there are no central fibers that project back into the retina). However, there is now increasing evidence that cortical sites also play an important role in afterimage formation (Shimojo et al., 2001; Gilroy and Blake, 2005; Tsuchiya and Koch, 2005); for example, removing stimuli from awareness by inter-ocular suppression decreases afterimage duration and strength (Gilroy and Blake, 2005; Tsuchiya and Koch, 2005).

Interestingly, attentional withdrawal increases afterimage durations (Lou, 2001; Suzuki and Grabowecky, 2003; Wede and Francis, 2007; Lak, 2008). This is quite counterintuitive because attention is thought to boost neuronal activity (Reynolds and Chelazzi, 2004; Reynolds and Heeger, 2009), which would result in stronger adaptation (Ling and Carrasco, 2006; Rezec et al., 2004), leading to longer afterimages.

Even though an attention-related decrease and an awarenessrelated increase of afterimage strength and duration have been shown separately, different stimuli and different tasks were employed. It is essential that the effects of attention and consciousness be studied using identical stimuli and tasks. For example, stimulus parameters, such as the spatial frequency of the adaptor, are critical in determining the afterimage strength (Brascamp et al., 2010). Specifically, the decrease in afterimage duration with decreased visibility only occurs for low spatial frequency stimuli. For high-spatial frequency stimuli, a paradoxical increase in afterimage duration occurs with decreased visibility (Brascamp et al., 2010). These differences make previous research difficult to compare. Note that the increase in afterimage duration with decreased attention found in previous studies was obtained with high-spatial frequency stimuli.

A recent study (van Boxtel et al., 2010) addressed the separate influences of attention and awareness on afterimage perception, employing a full-factorial design while controlling stimulus and task confounds. Attention and awareness were independently manipulated during the afterimage induction phase, while the effects of these manipulations were measured in the afterimage perception phase. Attention to the afterimage inducer was manipulated by employing an attention-distracting task at fixation (i.e., the central task). This task could be easy or hard (Lavie, 1995; Bahrami et al., 2008b; Macdonald and Lavie, 2008), ensuring identical visual input while manipulating the levels of attention available to the afterimage inducer. The conscious visibility of the inducer stimulus was manipulated independently of attention by means of continuous flash suppression, a form of inter-ocular suppression (i.e., presenting a very salient object in one eye that completely suppresses the afterimage inducer in the other eye (Tsuchiya and Koch, 2005, see also Gilroy and Blake, 2005; Tsuchiya et al., 2006). With the suppression present, the Gabor patch inducing the afterimage was not perceived. This $2 \times 2$ design allowed for a full-factorial comparison (i.e., high attention/visible, low attention/visible, high attention/ invisible, and low attention/invisible).

van Boxtel et al. (2010) found that attention decreased the duration of the afterimage while awareness increased the duration of the afterimage. In other words: the effects of attention and awareness opposed each other at the level of perception (see Figure 3D). There was no interaction between the effects of attention and consciousness. In the above experiment the change in conscious visibility was induced by a stimulus change. To remove the artifacts associated with the stimulus change, we utilized random fluctuations in visibility due to binocular rivalry, and due to Troxler fading and confirmed similar results (van Boxtel et al., 2010).

In a related study, the effects of attention and consciousness on afterimages were investigated over a range of spatial frequencies (Brascamp et al., 2010). Using signal detection theory, these authors showed that the difference between the effects of attention and awareness can be pinned down to the different manner in which attention and awareness influence different visual channels. Briefly, afterimage duration is determined by the strength of adaptation of both phase-sensitive and phase-insensitive visual channels (Suzuki and Grabowecky, 2003; Wede and Francis, 2007; Francis, 2010). The afterimage appears stronger when the adaptation of phase-sensitive channels is increased, because afterimages originate from this adaptation. In contrast, when adaptation in phase-insensitive channels is increased the afterimage looks weaker, because this adaptation increases detection thresholds, thus making the afterimage harder to see (Leguire and Blake, 1982; Georgeson and Turner, 1985). Brascamp and colleagues showed that attention and consciousness increased adaptation in both channels, and that afterimage durations reflect the balance between these two factors. The observed opposite effects of afterimage durations at the perceptual level are caused by a change in balance between both channels (due to adaptation), rather than being due to opposite effects at an early neural level. Interestingly, however, the adaptation effects of attention and consciousness were correlated for phase-insensitive adaptation, while they were uncorrelated for phase-sensitive adaptation (Brascamp et al., 2010).

Taken together Brascamp et al. (2010) and van Boxtel et al. (2010) showed that attention and consciousness can have opposing effects on visual perception, while still performing similar, yet not identical, operations at a neural level. Whether this finding is limited to afterimages or is a more common phenomenon remains open.

We have reviewed data that suggest some type of functional dissociation between attention and consciousness. But what are the respective anatomical and neuronal bases? This question is hard to answer, and would require a whole other review article. Effects of consciousness (e.g., Rees et al., 2002) and attention (e.g., Corbetta and Shulman, 2002) have been found throughout the brain. However, no fMRI study has used a $2 \times 2$ factorial design to dissect the anatomical underpinnings of attention and consciousness, making it difficult to assign one or another brain area to either attention or consciousness. Wyart and Tallon-Baudry (2008) have performed an experiment pitting attention against consciousness, but the MEG signals did not allow for precise anatomic localization (but they did show a separable influence of attention and consciousness on different frequency bands in the MEG signal).

There are some striking parallels between the two-stream hypothesis for perception and action on the one hand (Trevarthen, 1968; Ungerleider and Mishkin, 1982; Milner and Goodale, 1993, 2008 ), and the division between attention and consciousness on the other hand.

Attention primarily reduces the complexity of incoming input so that the brain can process it online and in real time. This might/ could be the function of Milner and Goodale's (2008) dorsal visual 
stream for action. In fact, the "pre-motor" theory of attention (Rizzolatti et al., 1987) argues that visual attention evolved from the need to plan to move the eyes to one location. Overt eye movements and covert attention are closely related in both neural and functional ways. In terms of anatomical structure, front-parietal areas have been implicated in the control of attention (e.g., Corbetta and Shulman, 2002), which are, of course, part of the dorsal, vision-for-action pathway.

On the other hand, the ventral, vision-for-perception pathway has been linked to consciousness (Milner and Goodale, 1993, 2008; Tong et al., 1998; Rees et al., 2002).

As pointed out by Milner and Goodale (2008), the two streams interact intensely under most circumstances but they can be dissociated in neurological patients and in normal subjects with some illusions. A similar point could be made for attention and consciousness. From this perspective, many examples of attention without consciousness may be thought of as normal functioning of dorsal attention orienting system without proper/full ventral functioning (see e.g., Jiang et al., 2006; Lambert and Shin, 2010). The key here is that there are some recognition modules present in the dorsal pathways (e.g., shape sensitivity, Lehky and Sereno, 2007). An object, or location, may attract attention without giving rise to consciousness via this pathway (cf. Lambert and Shin, 2010).

Likewise, consciousness without attention may be due to some ventral function without the help of attentional amplification from the dorsal systems (as in dual-task paradigms, e.g., Reddy et al., 2007). This could be because, for example, a face module in FFA is effectively activated without the help of attentional system.

Even though linking consciousness primarily to the ventral stream and attention to the dorsal stream is undoubtedly an oversimplification, especially in the light of known strong and reciprocal anatomical interactions among these streams (Baizer et al., 1991), as well as the variety in types of attention (e.g., endogenous versus exogenous, focused versus object-based), framing the attention/ consciousness difference along these anatomical lines may help us better define future research directions.

\section{REFERENCES}

Alpern, M., and Barr, L. (1962). Durations of the after-images of brief light flashes and the theory of the Broca and Sulzer phenomenon. J. Opt. Soc. Am. 52, 219-221.

Alvarez, G. A., and Cavanagh, P. (2005). Independent resources for attentional tracking in the left and right visual hemifields. Psychol. Sci. 16, 637-643.

Alvarez, G. A., and Oliva, A. (2008). The representation of simple ensemble visual features outside the focus of attention. Psychol. Sci. 19, 392-398.

Alvarez, G.A., and Oliva, A. (2009). Spatial ensemble statistics are efficient codes that can be represented with reduced attention. Proc. Natl. Acad. Sci. U.S.A. 106, 7345-7350.

Ansorge, U., and Neumann, O. (2005). Intentions determine the effect of invisible metacontrast-masked

\section{CONCLUSION}

Here, we reviewed additional evidence for a dissociation between top-down, selective attention and consciousness. We find that there exists considerable evidence for attentional deployment without consciousness, supporting the view that attention is not sufficient for consciousness. We also reviewed evidence for consciousness without attention, which indicates that attention is not necessary for consciousness. Yet many scholars find the evidence for this latter claim insufficiently compelling. We believe that psychophysical studies are not powerful enough to decide this question. In particular, it may never be possible to fully prevent subjects paying some attention to a stimulus on the basis of purely behavioral techniques. Currently, many assume that an important means by which topdown attention influence sensory processing is via cortico-cortical feedback connections (Macknik and Martinez-Conde, 2007). It may be possible to transiently, delicately, reversibly and specifically knock out all top-down cortico-cortical pathways, thereby preventing the subject, most likely a mouse or non-human primate, from exerting any sort of top-down attentional control. This could be achieved via molecular-biology tools, in particular opto-genetics (Han et al., 2009; Gradinaru et al., 2010). Unbraiding the complex relationship between attention and consciousness will ultimately depend on such powerful, interventionist tools.

\section{ACKNOWLEDGMENTS}

Jeroen J.A.van Boxtel is supported by a Rubicon grant of the Netherlands Organisation of Scientific Research. Naotsugu Tsuchiya is supported by the Japan Society for the Promotion of Science. We thank Patrick Cavanagh and other audience members at the Rovereto Attention Workshop in 2009 and at the workshop at Vision Science Society 2010 for a stimulating discussion, and Jan Brascamp for comments on the manuscript. The research discussed here is supported by the National Science Foundation, the Mathers Foundation, the Gimbel Fund and the WCU program through the National Research Foundation of Korea, funded by the Ministry of Education, Science and Technology (R31-2008-000-10008-0) to Christof Koch. We thank the two reviewers for their helpful and insightful comments and suggestions.

Bahrami, B., Carmel, D., Walsh, V., Rees, G., and Lavie, N. (2008b). Unconscious orientation processing depends on perceptual load. J. Vis. 8, 1-10.

Bahrami, B., Lavie, N., and Rees, G. (2007). Attentional load modulates responses of human primary visual cortex to invisible stimuli. Curr. Biol. 17, 509-513.

Baizer, J. S., Ungerleider, L. G., and Desimone, R. (1991). Organization of visual inputs to the inferior temporal and posterior parietal cortex in macaques. J. Neurosci. 11, 168-190.

Bauer, F., Cheadle, S. W., Parton, A., Muller, H. J., and Usher, M. (2009). Gamma flicker triggers attentional selection without awareness. Proc. Natl. Acad. Sci. U.S.A. 106, 1666-1671.

Beilock, S. L., Carr, T. H., MacMahon, C., and Starkes, J. L. (2002). When paying attention becomes counterproductive: impact of divided versus skill-focused attention on novice and experienced performance of sensorimotor skills. J. Exp. Psychol. Appl. 8, 6-16.

Biederman, I. (1972). Perceiving realworld scenes. Science 177, 77-80.

Block, N. (2005). Two neural correlates of consciousness. Trends Cogn. Sci. 9, 46-52.

Block, N. (2007). Consciousness, accessibility, and the mesh between psychology and neuroscience. Behav. Brain Sci. 30, 481-499; discussion 499-548.

Bonneh, Y. S., Cooperman, A., and Sagi, D. (2001). Motion-induced blindness in normal observers. Nature 411, 798-801.

Brascamp, J. W., van Boxtel, J. J., Knapen, T., and Blake, R. (2010). A dissociation of attention and awareness in phasesensitive but not phase-insensitive 
visual channels. J. Cogn. Neurosci. 22, 2326-2344.

Braun, J. (2007). Vision: attending the invisible. Curr. Biol. 17, R202-R203.

Braun, J., and Julesz, B. (1998). Withdrawing attention at little or no cost: detection and discrimination tasks. Percept. Psychophys. 60, 1-23.

Braun, J., and Sagi, D. (1990). Vision outside the focus of attention. Percept. Psychophys. 48, 45-58.

Brindley, G. S. (1962). Two new properties of foveal after-images and a photochemical hypothesis to explain them. J. Physiol. 164, 168-179.

Chica, A. B., Lasaponara, S., Lupianez, J., Doricchi, F., and Bartolomeo, P. (2010). Exogenous attention can capture perceptual consciousness: ERP and behavioural evidence. Neuroimage 51, 1205-1212.

Choi, H., Seitz, A. R., and Watanabe, T. (2009). When attention interrupts learning: inhibitory effects of attention on TIPL. Vision Res. 49, 2586-2590.

Chong, S. C., Tadin, D., and Blake, R. (2005). Endogenous attention prolongs dominance durations in binocular rivalry. J. Vis. 5, 1004-1012.

Chun, M. M., and Potter, M. C. (1995). A two-stage model for multiple target detection in rapid serial visual presentation. J. Exp. Psychol. Hum. Percept. Perform. 21, 109-127.

Chun, M. M., and Wolfe, J. M. (2000). "Visual attention," in Blackwell's Handbook of Perception, ed. E. B. Goldstein (oxford, UK: Blackwell publications), 272-310.

Corbetta, M., and Shulman, G. L. (2002). Control of goal-directed and stimulusdriven attention in the brain. Nat. Rev. Neurosci. 3, 201-215.

De Brigard, F., and Prinz, J. (2010). Attention and consciousness. Wiley Interdiscip. Rev. Cogn. Sci. 1, 51-59.

de Gardelle, V., Sackur, J., and Kouider, S. (2009). Perceptual illusions in brief visual presentations. Conscious. Cogn. $18,569-577$.

Dehaene, S., Changeux, J. P., Naccache, L., Sackur, J., and Sergent, C. (2006). Conscious, preconscious, and subliminal processing: a testable taxonomy. Trends Cogn. Sci. 10, 204-211.

Desimone, R., and Duncan, J. (1995). Neural mechanisms of selective visual attention. Annu. Rev. Neurosci. 18, 193-222.

Driver, J. (1998). "The neuropsychology of spatial attention," in Attention Studies in Cognition, ed. H. Pashler (Philadelphia, PA: Psychology Press). 297-340.

Duncan, J. (1998). Converging levels of analysis in the cognitive neuroscience of visual attention. Philos. Trans. R. Soc. Lond. B Biol. Sci. 353, 1307-1317.
Duncan, J., Martens, S., and Ward, R. (1997). Restricted attentional capacity within but not between sensory modalities. Nature 387, 808-810.

Einhäuser, W., Koch, C., and Makeig, S. (2007). The duration of the attentional blink in natural scenes depends on stimulus category. Vision Res. 47, 597-607.

Evans, K. K., and Treisman, A. (2005). Perception of objects in natural scenes: is it really attention free? J. Exp. Psychol. Hum. Percept. Perform. 31, 1476-1492.

Fei-Fei, L., Iyer, A., Koch, C., and Perona, P. (2007). What do we perceive in a glance of a real-world scene? J. Vis. $7,10$.

Fei-Fei, L., VanRullen, R., Koch, C., and Perona, P. (2002). Rapid natural scene categorization in the near absence of attention. Proc. Natl. Acad. Sci. U.S.A. 99, 9596-9601.

Finkbeiner, M., and Palermo, R. (2009). The role of spatial attention in nonconscious processing: a comparison of face and non-face stimuli. Psychol. Sci. 20, 42-51.

Francis, G. (2010). Modeling filling-in of afterimages. Atten. Percept. Psychophys. $72,19-22$.

Geng, H.-Y., Song, Q.-L., Li, Y.-F., Xu, S., and Zhu, Y. (2007). Attentional modulation of motion-induced blindness. Chin. Sci. Bull. 52, 1063-1070.

Georgeson, M.A., and Turner, R.S. (1985). Afterimages of sinusoidal, squarewave and compound gratings. Vision Res. 25, 1709-1720.

Gilroy, L. A., and Blake, R. (2005). The interaction between binocular rivalry and negative afterimages. Curr. Biol. 15, 1740-1744.

Gradinaru, V., Zhang, F., Ramakrishnan, C., Mattis, J., Prakash, R., Diester, I., Goshen, I., Thompson, K. R., and Deisseroth, K. (2010). Molecular and cellular approaches for diversifying and extending optogenetics. Cell 141, 154-165.

Han, X., Qian, X., Bernstein, J. G., Zhou, H. H., Franzesi, G. T., Stern, P., Bronson, R. T., Graybiel, A. M., Desimone, R., and Boyden, E. S. (2009). Millisecondtimescale optical control of neural dynamics in the non-human primate brain. Neuron 62, 191-198.

Hardcastle, V. G. (1997). Attention versus consciousness: a distinction with a difference. Cogn. Stud. Bull. Jpn. Cogn. Sci. Soc. 4, 56-66.

He, S., Cavanagh, P., and Intriligator, J. (1996). Attentional resolution and the locus of visual awareness. Nature 383, 334-337.

Hesselmann, G., Kell, C. A., Eger, E., and Kleinschmidt,A. (2008). Spontaneous local variations in ongoing neural activity bias perceptual decisions.
Proc. Natl. Acad. Sci. U.S.A. 105, 10984-10989.

Houtkamp, R., and Braun, J. (2010). Cortical response to task-relevant stimuli presented outside the primary focus of attention. J. Cogn. Neurosci. 22, 1980-1992.

Itti,L., and Koch, C. (2001).Computational modelling of visual attention. Nat. Rev. Neurosci. 2, 194-203.

Iwasaki, S. (1993). Spatial attention and two modes of visual consciousness. Cognition 49, 211-233.

Jackendoff, R. (1996). How language helps us think. Pragmat. Cogn. 4, 1-34.

James, W. (1890). Principles of Psychology. London: MacMillan.

Jiang, Y., Costello, P., Fang, F., Huang, M., and He, S. (2006). A gender- and sexual orientation-dependent spatial attentional effect of invisible images. Proc. Natl. Acad. Sci. U.S.A. 103 , 17048-17052.

Kanai, R., Tsuchiya, N., and Verstraten, F. A. (2006). The scope and limits of top-down attention in unconscious visual processing. Curr. Biol. 16, 2332-2336.

Kentridge, R. W., Heywood, C. A., and Weiskrantz, L. (1999a). Attention without awareness in blindsight. Proc. Biol. Sci. 266, 1805-1811.

Kentridge, R. W., Heywood, C. A., and Weiskrantz, L. (1999b). Effects of temporal cueing on residual visual discrimination in blindsight. Neuropsychologia 37, 479-483.

Kentridge, R. W., Heywood, C. A., and Weiskrantz,L. (2004). Spatial attention speeds discrimination without awareness in blindsight. Neuropsychologia 42, 831-835.

Kentridge, R. W., Nijboer, T. C., and Heywood, C. A. (2008). Attended but unseen: visual attention is not sufficient for visual awareness. Neuropsychologia 46, 864-869.

Kiefer, M., and Brendel, D. (2006). Attentional modulation of unconscious, ,automatic” processes: evidence from event-related potentials in a masked priming paradigm. J. Cogn. Neurosci. 18, 184-198.

Koch, C. (2004). The Quest for Consciousness: A Neurobiological Approach. Englewood, CO: Roberts \& Company.

Koch, C., and Tsuchiya, N. (2007) Attention and consciousness: two distinct brain processes. Trends Cogn. Sci. 11, 16-22.

Kruschke, J. K. (2001). Toward a unified model of attention in associative learning. J. Math. Psychol. 45, 812-863.

Lak, A. (2008). Attention during adaptation weakens negative afterimages of perceptually colour-spread surfaces. Can. J. Exp. Psychol. 62, 101-109.
Lambert, A. J., and Shin, M.-J. (2010). The hare and the snail: dissociating visual orienting from conscious perception. Vis. cogn. 18, 829-838.

Lamme, V.A. (2003). Why visual attention and awareness are different. Trends Cogn. Sci. 7, 12-18.

Lamme, V. A. (2010). How neuroscience will change our view on consciousness. Cogn. Neurosci. 1, 204-220.

Lavie, N. (1995). Perceptual load as a necessary condition for selective attention. J. Exp. Psychol. Hum. Percept. Perform. 21, 451-468.

Lee, D. K., Itti, L., Koch, C., and Braun, J. (1999a). Attention activates winnertake-all competition among visual filters. Nat. Neurosci. 2, 375-381.

Lee, D. K., Koch, C., and Braun, J. (1999b). Attentional capacity is undifferentiated: concurrent discrimination of form, color, and motion. Percept. Psychophys. 61, 1241-1255.

Leguire, L. E., and Blake, R. (1982). Role of threshold in afterimage visibility. J. Opt. Soc. Am. 72, 1232-1237.

Lehky, S. R., and Sereno, A. B. (2007). Comparison of shape encoding in primate dorsal and ventral visual pathways. J. Neurophysiol. 97, 307-319.

Lin, J. Y., Franconeri, S., and Enns, J. T. (2008). Objects on a collision path with the observer demand attention. Psychol. Sci. 19, 686-692.

Lin, J. Y., Murray, S. O., and Boynton, G. M. (2009). Capture of attention to threatening stimuli without perceptual awareness. Curr. Biol. 19, 1118-1122.

Lin, Z., and He, S. (2009). Seeing the invisible: the scope and limits of unconscious processing in binocular rivalry. Prog. Neurobiol. 87, 195-211.

Ling, S., and Carrasco, M. (2006). When sustained attention impairs perception. Nat. Neurosci. 9, 1243-1245.

Logan, G. D., and Crump, M. J. C. (2009). The left hand doesn't know what the right hand is doing: the disruptive effects of attention to the hands in skilled typewriting. Psychol. Sci. 20, 1296-1300.

Loomis, J. M. (1972). The photopigment bleaching hypothesis of complementary after-images: a psychophysical test. Vision Res. 12, 1587-1594.

Loomis, J. M. (1978). Complementary afterimages and the unequal adapting effects of steady and flickering light. J. Opt. Soc. Am. 68, 411-416.

Lou, L. (1999). Selective peripheral fading: evidence for inhibitory sensory effect of attention. Perception 28, 519-526.

Lou, L. (2001). Effects of voluntary attention on structured afterimages. Perception 30, 1439-1448.

Macdonald, J. S., and Lavie, N. (2008). Load induced blindness. J. Exp. Psychol. Hum. Percept. Perform. 34, 1078-1091. 
Mack,A., and Rock, I. (1998). Inattentional Blindness. Cambridge, MA: MIT Press.

Macknik, S. L., and Martinez-Conde, S. (2007). The role of feedback in visual masking and visual processing. $A d v$. Cogn. Psychol. 3, 125-152.

Martini, P., and Maljkovic, V. (2009). Short-term memory for pictures seen once or twice. Vision Res. 49, 1657-1667.

Melcher, D., Papathomas, T. V., and Vidnyánszky, Z. (2005). Implicit attentional selection of visual features. Neuron 46, 723-729.

Merikle, P. M., and Joordens, S. (1997). Parallels between perception without attention and perception without awareness. Conscious. Cogn. 6, 219-236.

Meteyard, L., Zokaei, N., Bahrami, B., and Vigliocco, G. (2008). Visual motion interferes with lexical decision on motion words. Curr. Biol. 18, R732-R733.

Milner, A. D., and Goodale, M. A. (1993). Visual pathways to perception and action. Prog. Brain Res. 95, 317-337.

Milner, A. D., and Goodale, M. A. (2008). Two visual systems re-viewed. Neuropsychologia 46, 774-785.

Mole, C. (2008). Attention and consciousness. J. conscious. stud. 15, 86-104.

Montaser-Kouhsari, L., and Rajimehr, R. (2004). Attentional modulation of adaptation to illusory lines. J. Vis. 4, 434-444.

Morrone, M. C., Denti, V., and Spinelli, D. (2002). Color and luminance contrasts attract independent attention. Curr. Biol. 12, 1134-1137.

Naccache, L., Blandin, E., and Dehaene, S. (2002). Unconscious masked priming depends on temporal attention. Psychol. Sci. 13, 416-424.

Olivers, C. N., and Nieuwenhuis, S. (2005). The beneficial effect of concurrent taskirrelevant mental activity on temporal attention. Psychol. Sci. 16, 265-269.

O'Regan, J. K., and Noe, A. (2001). A sensorimotor account of vision and visual consciousness. Behav. Brain Sci. 24, 939-973; discussion 973-1031.

Pastukhov, A., Fischer, L., and Braun, J. (2009). Visual attention is a single, integrated resource. Vision Res. 49, 1166-1173.

Peelen, M. V., Fei-Fei, L., and Kastner, S. (2009). Neural mechanisms of rapid natural scene categorization in human visual cortex. Nature 460, 94-97.

Persaud, N., McLeod, P., and Cowey, A. (2007). Post-decision wagering objectively measures awareness. Nat. Neurosci. 10, 257-261.

Posner, M.I. (1994). Attention: the mechanisms of consciousness. Proc. Natl. Acad. Sci. U.S.A. 91, 7398-7403.
Prinz, J. (2010). "When is perception conscious?" in Perceiving the World: New Essays on Perception, ed. B. Nanay (New York: Oxford University Press), 310-332.

Rajimehr, R. (2004). Unconscious orientation processing. Neuron 41, 663-673.

Raymond, J. E., Shapiro, K. L., and Arnell, K. M. (1992). Temporary suppression of visual processing in an RSVP task: an attentional blink? J. Exp. Psychol. Hum. Percept. Perform. 18, 849-860.

Reber, A. S. (1976). Implicit learning of synthetic languages: the role of instructional set. J. Exp. Psychol. Hum. Learn. Mem. 2, 88-94.

Reddy, L., Moradi, F., and Koch, C. (2007). Top-down biases win against focal attention in the fusiform face area. Neuroimage 38, 730-739.

Reddy, L., Reddy, L., and Koch, C. (2006). Face identification in the near-absence of focal attention. Vision Res. 46, 2336-2343.

Reddy, L., Wilken, P., and Koch, C. (2004). Face-gender discrimination is possible in the near-absence of attention. J. Vis. 4, 106-117.

Rees, G., Kreiman, G., and Koch, C. (2002). Neural correlates of consciousness in humans. Nat. Rev. Neurosci. 3, 261-270.

Rensink, R. A., O’Regan, J. K., and Clark, J. J. (1997). To see or not to see: the need for attention to perceive changes in scenes. Psychol. Sci. 8, 368-373.

Reynolds, J. H., and Chelazzi, L. (2004). Attentional modulation of visual processing. Annu. Rev. Neurosci. 27, 611-647.

Reynolds, J. H., and Heeger, D. J. (2009). The normalization model of attention. Neuron 61, 168-185.

Rezec, A., Krekelberg, B., and Dobkins, K. R. (2004). Attention enhances adaptability: evidence from motion adaptation experiments. Vision Res. 44, 3035-3044.

Rizzolatti, G., Riggio, L., Dascola, I., and Umilta, C. (1987). Reorienting attention across the horizontal and vertical meridians: evidence in favor of a premotor theory of attention. Neuropsychologia 25, 31-40.

Sakitt, B. (1976). Psychophysical correlates of photoreceptor activity. Vision Res. 16, 129-140.

Sampanes,A.C., Tseng, P., and Bridgeman, B. (2008). The role of gist in scene recognition. Vision Res. 48, 2275-2283.

Sato, W., Okada, T., and Toichi, M. (2007). Attentional shift by gaze is triggered without awareness. Exp. Brain Res. 183, 87-94.

Scholvinck, M. L., and Rees, G. (2009). Attentional influences on the dynamics of motion-induced blindness. J. Vis. 9, 31-39.

Sergent, C., and Dehaene, S. (2004). Is consciousness a gradual phenomenon? Evidence for an all-or-none bifurcation during the attentional blink. Psychol. Sci. 15, 720-728.

Shimojo, S., Kamitani, Y., and Nishida, S. (2001). Afterimage of perceptually filled-in surface. Science 293, 1677-1680.

Shin, K., Stolte, M., and Chong, S. C. (2009). The effect of spatial attention on invisible stimuli. Atten. Percept. Psychophys. 71, 1507-1513.

Sperling, G. (1960). The information available in brief visual presentations. Psychol. Monogr. 74, 1-29.

Sumner, P., Tsai, P. C., Yu, K., and Nachev, P. (2006). Attentional modulation of sensorimotor processes in the absence of perceptual awareness. Proc. Natl. Acad. Sci. U.S.A. 103, 10520-10525.

Suzuki, S., and Grabowecky, M. (2003). Attention during adaptation weakens negative afterimages. J. Exp. Psychol. Hum. Percept. Perform. 29, 793-807.

Swan, L. (2001). Unilateral spatial neglect. Phys. Ther. 81, 1572-1580.

Tapia, E., Breitmeyer, B. G., and Shooner, C. R. (2010). Role of task-directed attention in non-conscious and conscious response priming by form and color. J. Exp. Psychol. Hum. Percept. Perform. 36, 74-87.

Tong, F., Nakayama, K., Vaughan, J. T., and Kanwisher, N. (1998). Binocular rivalry and visual awareness in human extrastriate cortex. Neuron 21, 753-759.

Tononi, G. (2004). An information integration theory of consciousness. BMC Neurosci. 5, 42. doi:10.1186/14712202-5-42.

Tononi, G. (2008). Consciousness as integrated information: a provisional manifesto. Biol. Bull. 215, 216-242.

Torralba, A., Oliva, A., Castelhano, M. S., and Henderson, J. M. (2006). Contextualguidance of eye movements and attention in real-world scenes: the role of global features on object search. Psychol. Rev. 4, 766-786.

Trevarthen, C.B. (1968). Two mechanisms of vision in primates. Psychol. Forsch. 31, 299-348.

Troxler, I. P. V. (1804). "Über das verschwinden gegebener gegenstände innerhalb unseres gesichtskreises," in Ophthalmologische Bibliothek, Vol. 2. eds K. Himly and J. A. Schmidt (Jena: Springer), 1-53.

Tse, P. U. (2004). Mapping visual attention with change blindness: new directions for a new method. Cogn. Sci. 28, 241-258.

Tsuchiya, N., and Braun, J. (2007). Contrast thresholds for component motion with full and poor attention. J. Vis. $7,1$.

Tsuchiya, N., and Koch, C. (2005). Continuous flash suppression reduces negative afterimages. Nat. Neurosci. 8 , 1096-1101.

Tsuchiya, N., and Koch, C. (2008a). Attention and consciousness. Scholarpedia 3, 4173.

Tsuchiya, N., and Koch, C. (2008b). "The relationship between consciousness and attention," in The Neurology of Consciousness, eds G. Tononi and S. Laureys (Oxford: Elsevier Academic), 63-77.

Tsuchiya, N., Koch, C., Gilroy, L. A., and Blake, R. (2006). Depth of interocular suppression associated with continuous flash suppression, flash suppression, and binocular rivalry. J. Vis. 6 , 1068-1078.

Tsushima, Y., Sasaki, Y., and Watanabe, T. (2006). Greater disruption due to failure of inhibitory control on an ambiguous distractor. Science 314 , 1786-1788.

Tsushima, Y., Seitz, A. R., and Watanabe, T. (2008). Task-irrelevant learning occurs only when the irrelevant feature is weak. Curr. Biol. 18, R516-R517.

Ungerleider, L. G., and Mishkin, M. (1982). "Two cortical visual systems," in Analysis of Visual Behavior, eds D. J. Ingle, M. A. Goodale, and R. J. W. Mansfield (Cambridge: MIT Press), 549-586.

Vallar, G. (2001). Extrapersonal visual unilateral spatial neglect and its neuroanatomy. Neuroimage 14, S52-S58.

Vallar, G. (2007). Spatial neglect, BalintHomes' and Gerstmann's syndrome, and other spatial disorders. CNS Spectr. 12, 527-536.

van Boxtel, J. J.A., Tsuchiya, N., and Koch, C. (2010). Opposing effects of attention and consciousness on afterimages. Proc. Natl. Acad. Sci. U.S.A. 107, 8883-8888.

Van den Bussche, E., Hughes, G., Humbeeck, N. V., and Reynvoet, B. (2010). The relation between consciousness and attention: an empirical study using the priming paradigm. Conscious. Cogn. 19, 86-97.

Velmans, M. (1996). The Science of Consciousness. London: Routledge.

Virsu, V., and Laurinen, P. (1977). Longlasting afterimages caused by neural adaptation. Vision Res. 17, 853-860.

Voss, J. L., Baym, C. L., and Paller, K. A. (2008). Accurate forced-choice recognition without awareness of memory retrieval. Learn. Mem. 15, 454-459.

Voss, J. L., and Paller, K. A. (2009). An electrophysiological signature of unconscious recognition memory. Nat. Neurosci. 12, 349-355. 
Vuilleumier, P., Armony, J. L., Driver, J., and Dolan, R. J. (2001). Effects of attention and emotion on face processing in the human brain: an event-related fMRI study. Neuron 30, 829-841.

Wede, J., and Francis, G. (2007).Attentional effects on afterimages: theory and data. Vision Res. 47, 2249-2258.

Werner, S., and Thies, B. (2000). Is "change blindness" attenuated by domain-specific expertise? An expertnovices comparison of change detection in football images. Vis. $\operatorname{cog} n$. 1, 163-173.

Werth, R., von Cramon, D., and Zihl, J. (1986). Neglect: phänomene halbseitiger vernachlässigung nach hirnschädigung. [Neglect: the phenomena of unilateral neglect following brain damage]. Fortschr. Neurol. Psychiatr. 54, 21-32.

Wilimzig, C., Tsuchiya, N., Fahle, M., Einhauser, W., and Koch, C.
(2008). Spatial attention increases performance but not subjective confidence in a discrimination task. J. Vis. 8, 1-10.

Wilson, H. R. (1997). A neural model of foveal light adaptation and afterimage formation. Vis. Neurosci. 14, 403-423.

Wojciulik, E., and Kanwisher, N. (1998). Implicit visual attribute binding following bilateral parietal damage. Vis. cogn. 5, 157-181.

Wojciulik, E., Kanwisher, N., and Driver, J. (1998). Covert visual attention modulates face-specific activity in the human fusiform gyrus: fMRI study. J. Neurophysiol. 79, 1574-1578.

Wolfe, J. M., Horowitz, T. S., and Kenner, N. M. (2005). Cognitive psychology: rare items often missed in visual searches. Nature 435, 439-440.

Wolfe, J. M., Reinecke, A., and Brawn, P. (2006). Why don't we see changes?
The role of attentional bottlenecks and limited visual memory. Vis. cogn. 14, 749-780.

Womelsdorf, T., and Fries, P. (2007). The role of neuronal synchronization in selective attention. Curr. Opin. Neurobiol. 17, 154-160.

Woodman, G. F., and Luck, S. J. (2003) Dissociations among attention, perception, and awareness during objectsubstitution masking. Psychol. Sci. 14, 605-611.

Wundt, W. (1874). Grundzüge Der Physiologischen Psychologie. Leipzig: Engelmann.

Wyart, V., and Tallon-Baudry, C. (2008). Neural dissociation between visual awareness and spatial attention. $J$. Neurosci. 28, 2667-2679.

Conflict of Interest Statement: The authors declare that the research was conducted in the absence of any commercial or financial relationships that could be construed as a potential conflict of interest.

Received: 15 June 2010; paper pending published: 02 August 2010; accepted: 16 November 2010; published online: 20 December 2010.

Citation: van Boxtel JJA, Tsuchiya N and Koch C (2010) Consciousness and attention: on sufficiency and necessity. Front. Psychology 1:217. doi: 10.3389/ fpsyg.2010.00217

This article was submitted to Frontiers in Consciousness Research, a specialty of Frontiers in Psychology.

Copyright (c) 2010 van Boxtel, Tsuchiya and Koch. This is an open-access article subject to an exclusive license agreement between the authors and the Frontiers Research Foundation, which permits unrestricted use, distribution, and reproduction in any medium, provided the original authors and source are credited. 